Supporting Information

\title{
Dynamic Behavior of Charged Particles at the Nanopipette Orifice
}

Cong Xu, ${ }^{\dagger}, \|$ Yang Liu, ${ }^{\dagger, \S}$ Tianyi Xiong, ${ }^{\dagger}, \|$ Fei Wu, ${ }^{\dagger, \|}$ Ping Yu, ${ }^{*},+, \|$ Jianhua Wang§ and Lanqun Mao*,t,

${ }^{+}$Beijing National Laboratory for Molecular Sciences, Key Laboratory of Analytical Chemistry for Living Biosystems, Institute of Chemistry, the Chinese Academy of Sciences, Beijing 100190, China

${ }^{\ddagger}$ College of Chemistry, Beijing Normal University, Beijing 100875, China

$\S$ Research Center for Analytical Sciences, Department of Chemistry, College of Sciences,

Northeastern University, Shenyang 110819, China

\| University of Chinese Academy of Sciences, Beijing 100049, China

${ }^{*}$ Correspondence to: yuping@iccas.ac.cn and lqmao@bnu.edu.cn 


\section{Table of Contents}

$\begin{array}{ll}\text { 1. Nanoparticles Characterization S3 } & \text { Sha }\end{array}$

Figure S1. Images and size distribution of PS particles.

\section{Nanopipette Characterization}

Figure S2. Images of nanopipettes.

Figure S3. $I-V$ curves of bare and Nafion-modified nanopipette in $\mathrm{KCl}$.

Figure S4. I-V curves of bare and APTES-modified nanopipette in $\mathrm{KCl}$.

3. Simulated Distribution of $E$ and $\nabla\left|E^{2}\right|$

Figure S5. Simulated distribution of $\mathrm{E}$ and $\nabla\left|E^{2}\right|$

4. Details of Finite-Element Simulations

Figure S6. Schematic illustration of 2D axisymmetric model.

Figure S7. Mesh used in 2D axisymmetric model.

Figure S8. Simulated forces in relation to the distance $d$.

Table S1. Boundary conditions set in 2D axisymmetric model.

Table S2. Simulated equilibrium position and corresponding $\Delta I / I_{0}$.

4.2 2D model

Figure S9. Schematic illustration of 2D model.

Figure S10. Mesh used in 2D model.

Table S3. Boundary conditions set in 2D model.

Table S4. Simulated forces under different experimental conditions. 


\section{Nanoparticles Characterization}
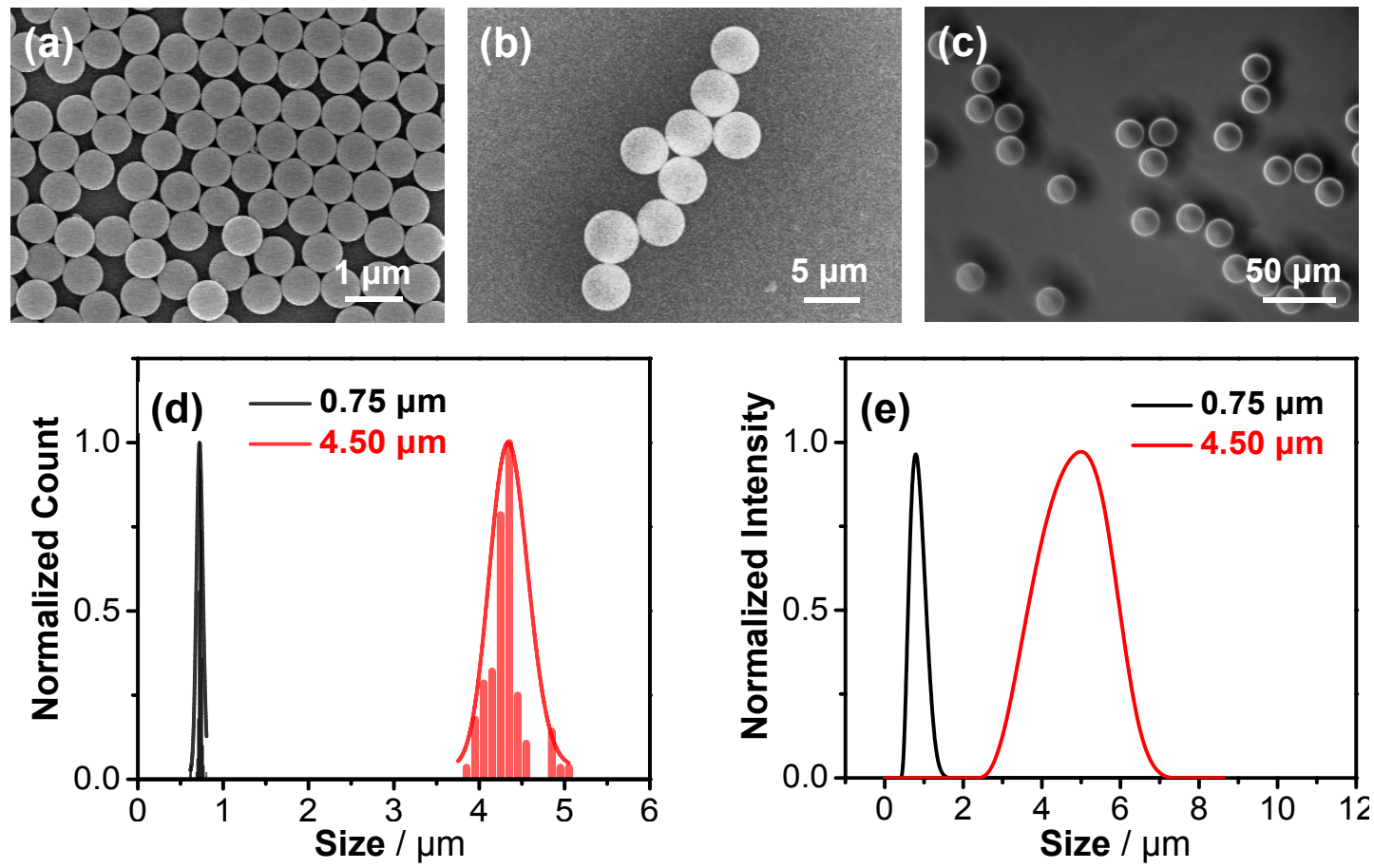

Figure S1. SEM images of PS particles with diameters of (a) $0.75 \mu \mathrm{m}$ and (b) 4.50 $\mu \mathrm{m}$; (c) optical microscopy images of PS particles with diameter of $20.0 \mu \mathrm{m}$. Size distribution of PS particles (d) derived from the statistical results according to SEM images and (d) obtained by dynamic light scattering (DLS) measurements. 


\section{Nanopipette Characterization}

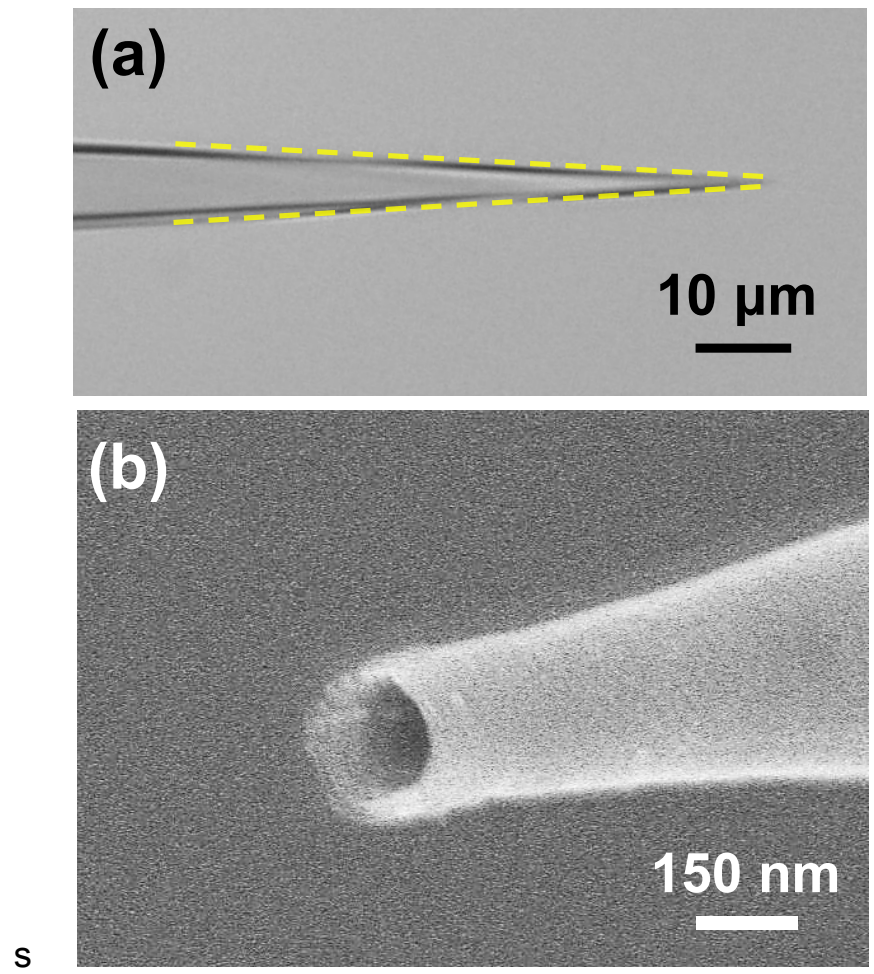

Figure S2. (a) Typical optical microscopy images and (b) scanning electron microscopy (SEM) images of nanopipette orifice. 


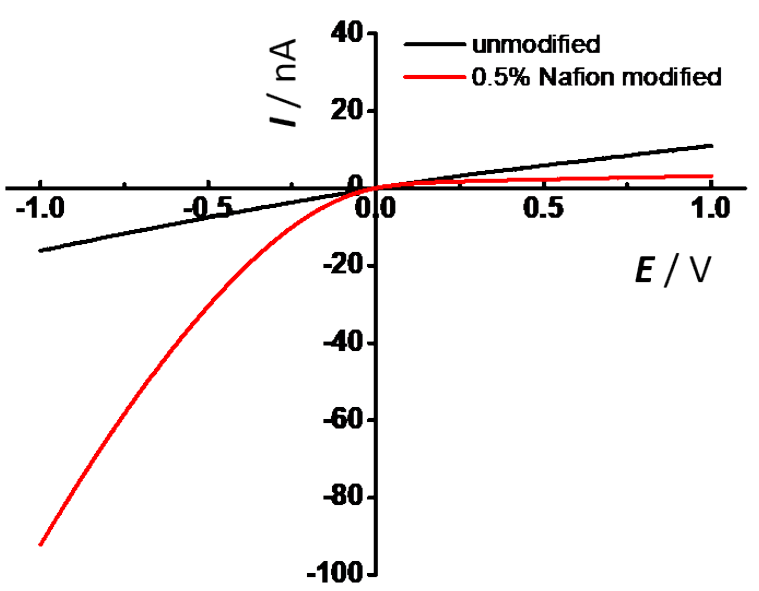

Figure S3. $I-V$ curves of bare (black line) and 0.5\% Nafion-modified (red line) nanopipettes in $100 \mathrm{mM} \mathrm{KCl}$, scan rate $50 \mathrm{mV} / \mathrm{s}$. 


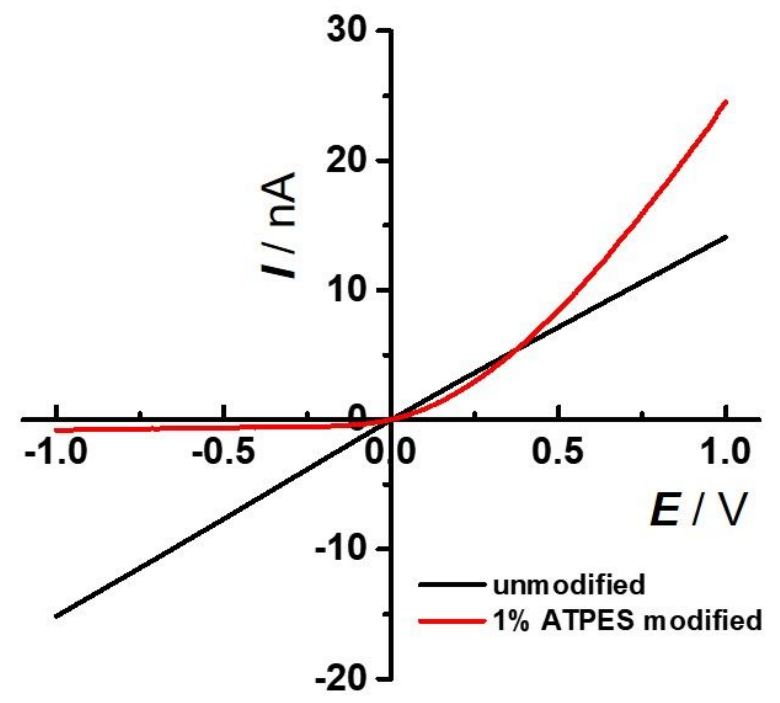

Figure S4. $I-V$ curves of bare (black line) and 1\% APTES-modified (red line) nanopipettes in $100 \mathrm{mM} \mathrm{KCl}$ solutions, scan rate $50 \mathrm{mV} / \mathrm{s}$. 
3. Simulated Distribution of $E$ and $\nabla\left|E^{2}\right|$

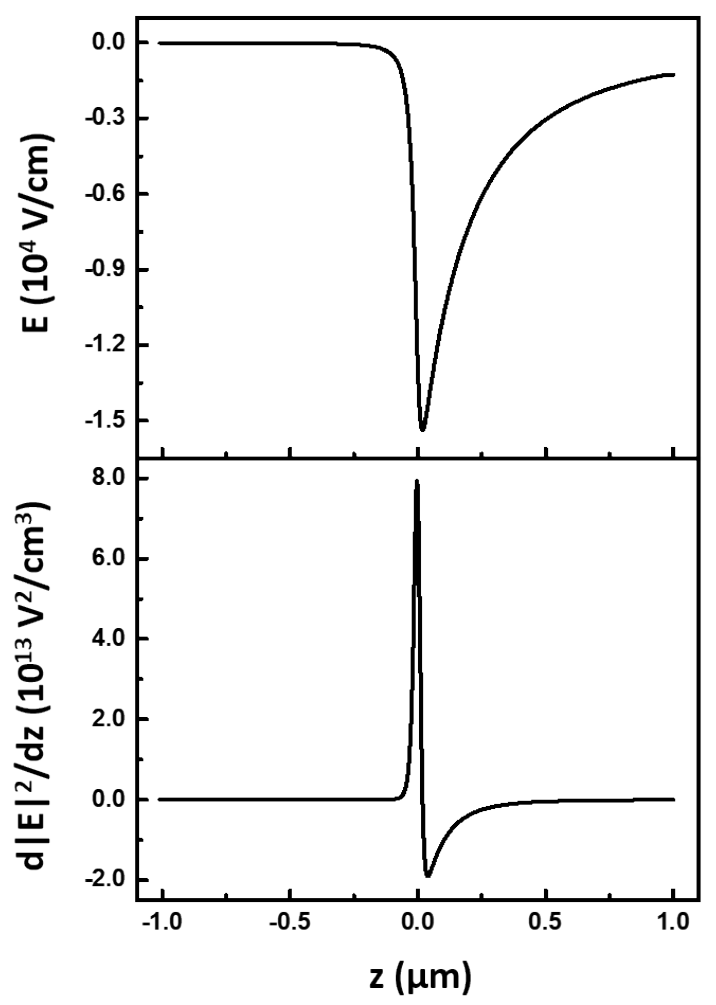

Figure S5. Simulated distribution of electric field $E$ and gradient of electric field norm squared $\nabla\left|\mathrm{E}^{2}\right|$ along z-axis under $0.5 \mathrm{~V}$ bias potential. 


\section{Details of Finite-Element Simulation Models}

The finite-element simulation of force condition on particles was carried out by the commercial software COMSOL Multiphysics 5.4 on a high-performance desktop computer. Figure S6 and S7 illustrate the established two-dimensional (2D) axisymmetric model and 2D model respectively, where a nanopipette of tip orifice radius $R_{\text {tip }}=70 \mathrm{~nm}$, wall thickness $T_{\text {tip }}=30 \mathrm{~nm}$ and half-cone angle $\alpha=4.5^{\circ}$ is immersed into a large reservoir containing the carboxyl functionalized polystyrene (PS) particle with radius $r$. Both the nanopipette and reservoir are filled with aqueous $\mathrm{KCl}$ solution of same concentration $c=100 \mathrm{mM}$. The liquid phase is assumed to be incompressible Newton fluid. In order to obtain the distribution of potential $\varphi$, the $i^{\text {th }}$ ionic species concentration $c_{i}$ and fluid velocity $\mathbf{u}$, the coupled Poisson-Nernst-Planck (PNP) and Navier-Stokes (NS) equations was numerically solved,

$$
\mathbf{J}_{i}=-D_{i} \nabla c_{i}-\frac{z_{i} F}{R T} D_{i} c_{i} \nabla \varphi+c_{i} \mathbf{u}
$$

where $\mathbf{J}_{i}, D_{i}$ and $z_{i}$ represent the flux, diffusion coefficient and charge of the $i^{\text {th }}$ ionic species respectively; $F, R, T$ represent Faraday constant, gas constant and absolute temperature respectively;

$$
\nabla^{2} \varphi=-\frac{F}{\varepsilon} \sum_{i} z_{i} c_{i}
$$

where $\varepsilon$ is the permittivity of solution;

$$
\mathbf{u} \nabla \mathbf{u}=\frac{1}{\rho}\left(-\nabla p+\eta \nabla^{2} \mathbf{u}-F \sum_{i} z_{i} c_{i} \nabla \varphi\right)=\mathbf{0}
$$

where $\rho$ and $\eta$ are the density and dynamic viscosity of the fluid, and $p$ is the hydrodynamic pressure.

The basic parameters are set as following: $D_{\mathrm{K}}{ }^{+}=1.96 \times 10^{-9} \mathrm{~m}^{2} \mathrm{~s}^{-1}, D_{\mathrm{Cl}}{ }^{-}=2.03 \times 10^{-}$ ${ }^{9} \mathrm{~m}^{2} \mathrm{~s}^{-1}, \varepsilon=80, \rho=1 \times 10^{3} \mathrm{~kg} \cdot \mathrm{m}^{-3}$ and $\eta=1 \times 10^{-3} \mathrm{~Pa} \cdot \mathrm{s}$. 


\subsection{D axisymmetric model}

Figure S6 shows the 2D axisymmetric model established to assess the effects of electrophoretic, electroosmotic and dielectrophoretic force on the charged particles. In this model, boundary 1 and 5 represent two $\mathrm{Ag} / \mathrm{AgCl}$ electrodes placed inside and outside the nanopipette, respectively. Boundary 2 and 3 represent the nanopipette wall and particle surface, respectively. Boundary 4 represents the central axis of particle. Boundary 6 and 7 represent the boundary of the reservoir filled with $\mathrm{KCl}$ electrolyte solution.

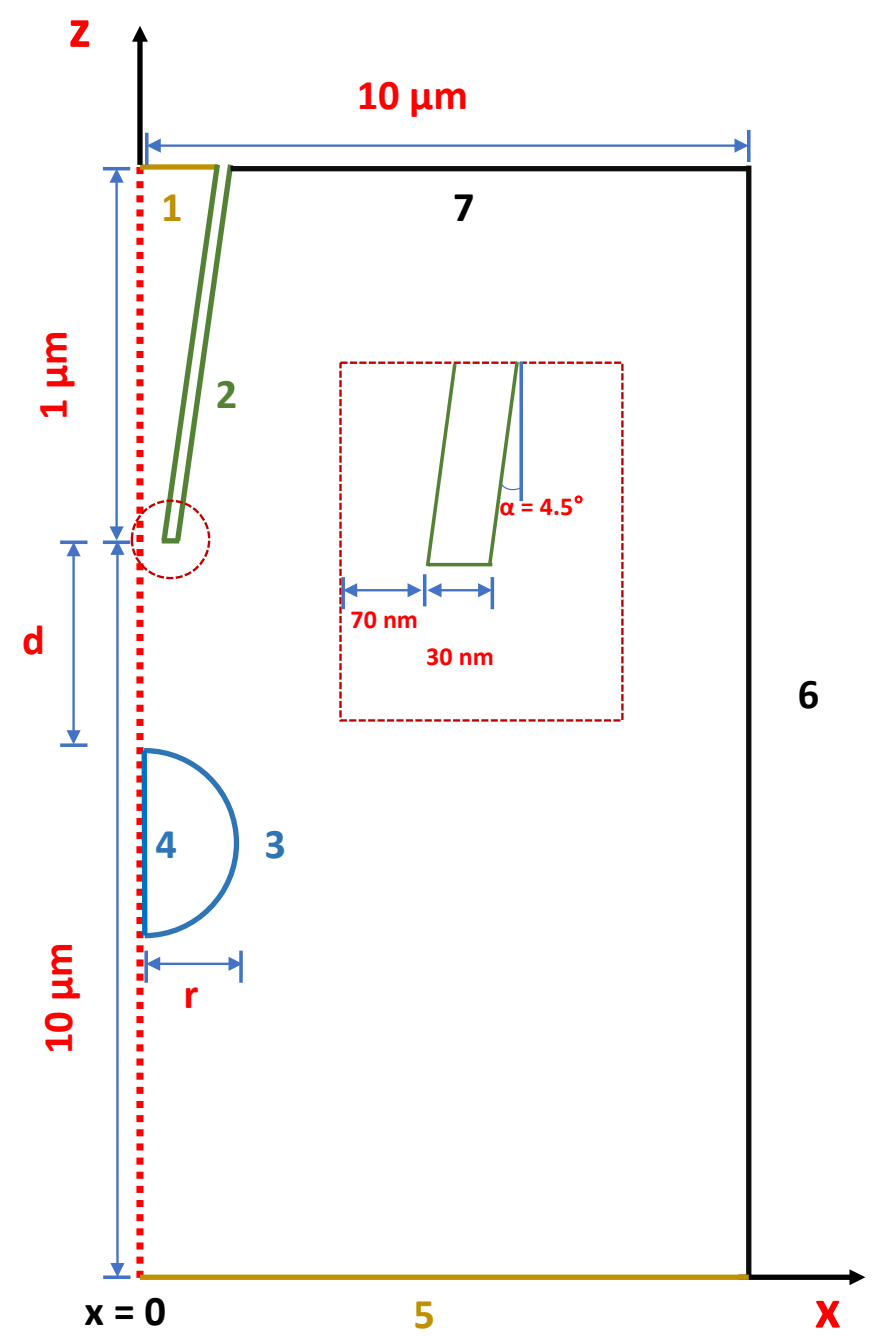

Figure S6. Schematic illustration of the established 2D axisymmetric model (not to scale). 

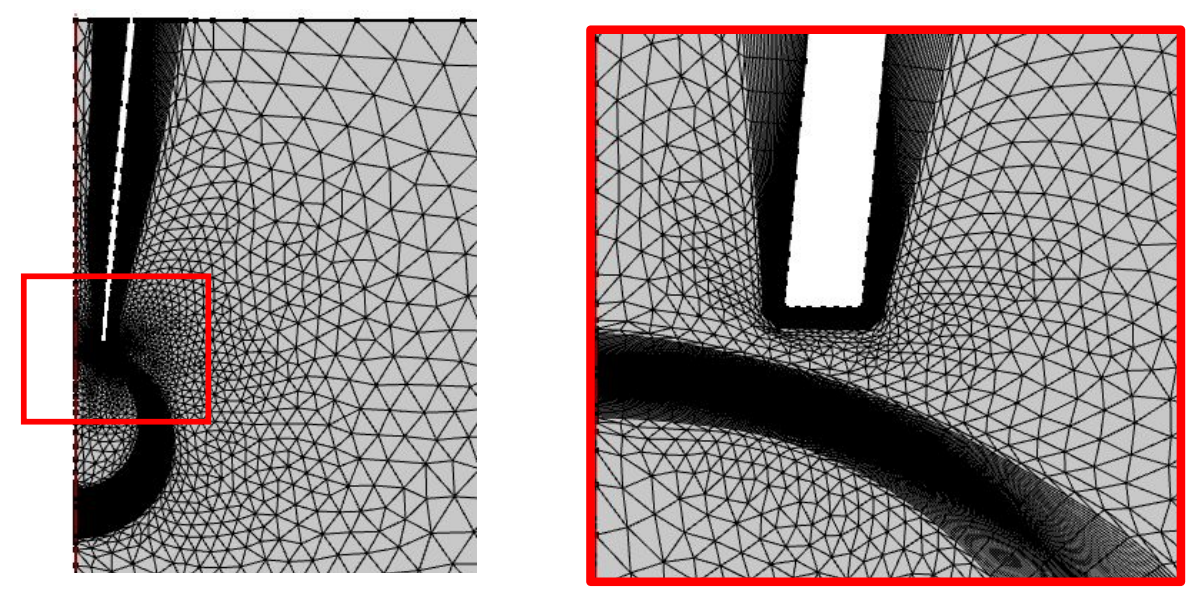

Figure S7. Mesh used in the established 2D axisymmetric model. Boundary 2 and boundary 3 are selected as the boundary layers. The number of these boundary layers is set to be 30 and the boundary layer stretching factor is set to be 1.02 . 
(a)

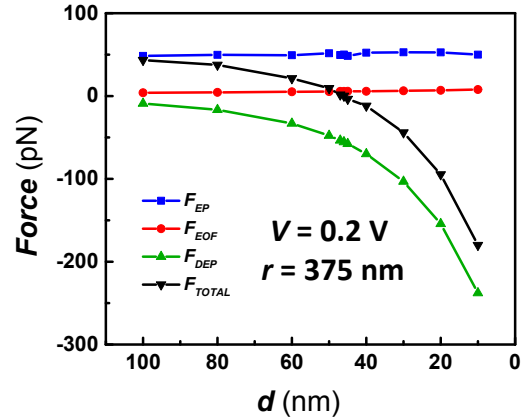

(c)

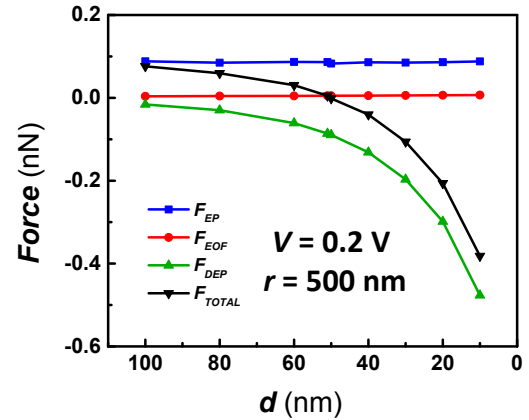

(b)

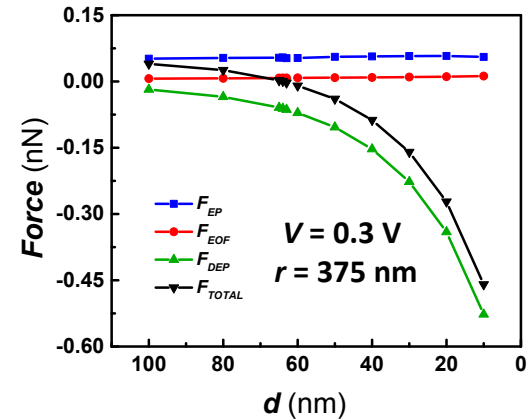

(d)

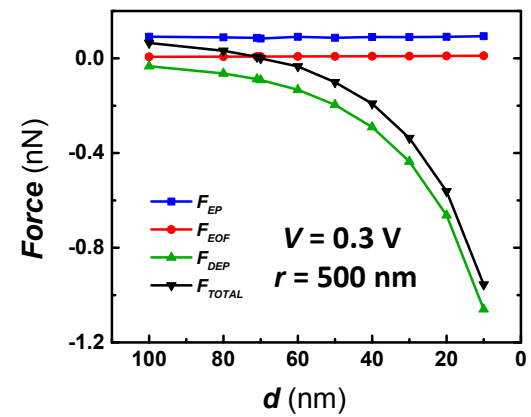

Figure S8. Simulated forces in relation to the distance $d$ between the nanopipette orifice and particles with different sizes under different applied bias voltage. 
Table S1. Boundary conditions set in the 2D axisymmetric model.

In the simulation, electric potential $V$ was applied to the $\mathrm{Ag} / \mathrm{AgCl}$ electrode placed inside the nanopipette (i.e., boundary 1). The surface charge densities at the nanopipette wall $\left(\rho_{N}\right)$ and particle surface $\left(\rho_{p}\right)$ were set equal to $-1 \mathrm{mC} / \mathrm{m}^{2}$ and -2 $\mathrm{mC} / \mathrm{m}^{2}$, respectively. The properties of the domain bounded by boundary 3 were set as Polystyrene (PS) in solid state, which was chosen from the build-in "Materials Library". The rest domain was defined to reflect the $\mathrm{KCl}$ electrolyte solution, with no flux and no slip at the nanopipette wall and particle surface.

\begin{tabular}{|c|c|c|}
\hline Boundary & Physical Description & Boundary Conditions \\
\hline 1 & $\begin{array}{l}\text { Ag/AgCl electrode } \\
\text { placed inside the } \\
\text { nanopipette }\end{array}$ & $\begin{array}{c}\varphi=V ; p=0 ; c_{i}=c_{i 0}=100 \mathrm{mM} \\
\mathbf{n} \cdot D_{i} \nabla c_{i}=0\end{array}$ \\
\hline 2 & Surface of nanopipette & $\rho_{N}=-1 \mathrm{mC} / \mathrm{m}^{2} ;-\mathbf{n} \cdot \mathbf{J}_{i}=0 ; \mathbf{u}=\mathbf{0}$ \\
\hline 3 & Surface of PS particle & $\begin{array}{c}\rho_{p}=-2 \mathrm{mC} / \mathrm{m}^{2} \\
r=375,500 \mathrm{~nm} ;-\mathbf{n} \cdot \mathbf{J}_{i}=0\end{array}$ \\
\hline 4 & $\begin{array}{l}\text { Central axis of PS } \\
\text { particle }\end{array}$ & / \\
\hline 5 & $\begin{array}{l}\mathrm{Ag} / \mathrm{AgCl} \text { electrode } \\
\text { placed outside the } \\
\text { nanopipette }\end{array}$ & $\begin{aligned} \varphi=0 ; p=0 ; c_{i} & =c_{i 0}=100 \mathrm{mM} \\
\mathbf{u} & =\mathbf{0}\end{aligned}$ \\
\hline 6,7 & $\begin{array}{l}\text { Boundary of the large } \\
\text { reservoir }\end{array}$ & $\begin{array}{c}\mathbf{u}=\mathbf{0} \text { on boundary } 6, \text { and } \\
\mathbf{n} \cdot D_{i} \nabla c_{i}=0 \text { on boundary } 7\end{array}$ \\
\hline
\end{tabular}

The ion current was calculated by $I=\int\left(\sum_{i} F z_{i} \mathbf{J}_{\mathrm{i}}\right) \cdot \mathbf{n} d \mathrm{~S}$, where $\mathrm{S}$ is the boundary 1 and $\mathbf{n}$ is the unit normal vector on the boundary 1.

The parameters of ion species were set as following: $D_{K}{ }^{+}=1.957 \times 10^{-9} \mathrm{~m}^{2} / \mathrm{s}, c_{K}{ }^{+}$ $=100 \mathrm{mM}, z_{K}{ }^{+}=+1, D_{C l}=2.032 \times 10^{-9} \mathrm{~m}^{2} / \mathrm{s}, c_{C l}=100 \mathrm{mM}, z_{C l}=-1$, and $\mathrm{T}=298 \mathrm{~K}$. It is noted that the surface charge densities of particle in different size were set as a unified value of $-2 \mathrm{mC} / \mathrm{m}^{2}$, rather than the value estimated from the measured zeta potential, resulted from the thin electric double layer (EDL) approximation. 
To be specific, the amount of net charge is relatively small owing to the existence of counter ions in the diffusion layer, causing a weakened $\boldsymbol{F}_{E P}$. Therefore, the particle surface charge densities were set as $-2 \mathrm{mC} / \mathrm{m}^{2}$ uniformly, on the boundary 3 where $\boldsymbol{F}_{E P}$ was calculated. 
Table S2. $d$ at the equilibrium position and relative ion current drop $\Delta I / I_{0}$ simulated under different bias potential by using particles in different size.

\begin{tabular}{cccc} 
Parameters Set & $\boldsymbol{d}(\mathbf{n m})$ & $\boldsymbol{\Delta I}(\mathbf{n} \boldsymbol{A})$ & $\Delta \boldsymbol{I} / \mathbf{I}_{\boldsymbol{o}}$ \\
\hline$V=0.2 \mathrm{~V}, \rho_{p}=-1 \mathrm{mC} / \mathrm{m}^{2}, r=250 \mathrm{~nm}$ & 50 & $9.48-9.20=0.28$ & $2.96 \%$ \\
\hline$V=0.3 \mathrm{~V}, \rho_{p}=-1 \mathrm{mC} / \mathrm{m}^{2}, r=250 \mathrm{~nm}$ & 70 & $14.21-13.95=$ & $1.82 \%$ \\
& & 0.26 & \\
\hline$V=0.2 \mathrm{~V}, \rho_{p}=-1 \mathrm{mC} / \mathrm{m}^{2}, r=375 \mathrm{~nm}$ & 46 & $9.48-9.20=0.28$ & $2.96 \%$ \\
\hline$V=0.3 \mathrm{~V}, \rho_{p}=-1 \mathrm{mC} / \mathrm{m}^{2}, r=375 \mathrm{~nm}$ & 64 & $14.21-13.96=$ & $1.77 \%$ \\
& & 0.25 &
\end{tabular}




\subsection{D model}

Figure S8 and S9 shows the geometry of 2D model and the mesh used in the model, respectively. The boundary conditions mentioned in Figure S8 are summarized in Table S3.

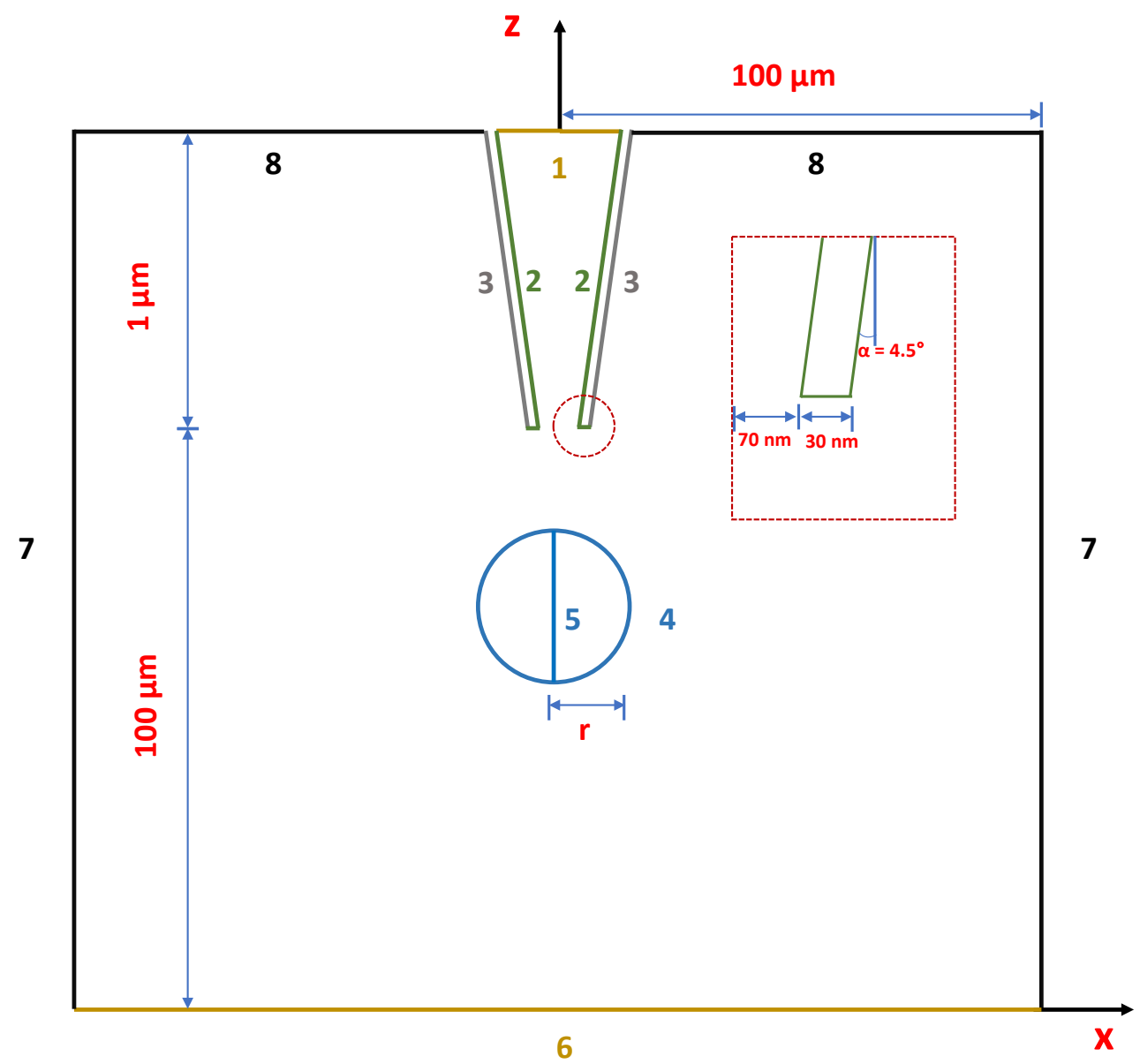

Figure S9. Schematic illustration of the established 2D model. 

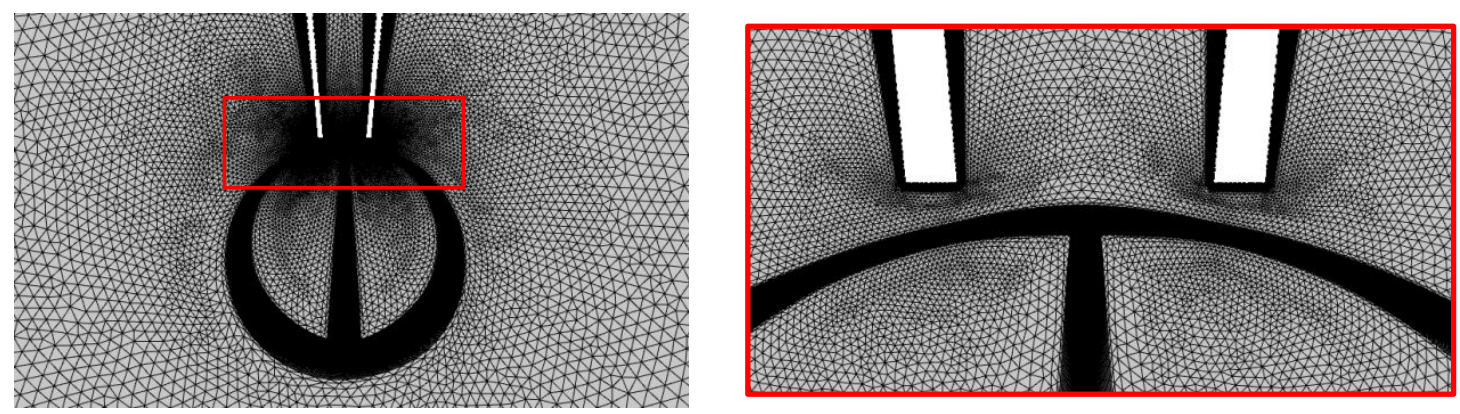

Figure S10. Mesh used in the established 2D model. 
Table S3. Boundary conditions set in the 2D model.

\begin{tabular}{ccc} 
Boundary & Physical Description & Boundary Conditions \\
\hline 1 & $\begin{array}{c}\text { Ag/AgCl electrode } \\
\text { placed inside the } \\
\text { nanopipette }\end{array}$ & $\varphi=V ; p=0 ; c_{i}=c_{i 0}=100 \mathrm{mM} ;$ \\
$\mathbf{n} \cdot D_{i} \nabla c_{i}=0$
\end{tabular}


Similarly, according to equation (1) - (3) in the main text, forces on the particle which deviate from the z-axis were calculated and summarized in Table S4.

Table S4. Simulated forces under different experimental conditions.

\begin{tabular}{|c|c|c|c|c|}
\hline Parameters Set & $F_{E P}$ & $F_{E O F}$ & $F_{D E P}$ & $F_{\text {TOTAL }}$ \\
\hline \multirow{2}{*}{$\begin{array}{c}V=0.8 \mathrm{~V}, \rho_{N}=-1 \mathrm{mC} / \mathrm{m}^{2}, \\
\rho_{p}=-1 \mathrm{mC} / \mathrm{m}^{2}, r=250 \mathrm{~nm} \\
\text { (Figure } 3 \mathrm{~b} \text { ) }\end{array}$} & $\mathrm{x}: 3.64 \mathrm{pN}$ & $\mathrm{x}: 8.73 \mathrm{pN}$ & $\mathrm{x}:-13.46 \mathrm{pN}$ & $\mathrm{x}:-1.08 \mathrm{pN}$ \\
\hline & $\mathrm{z:} 91.45 \mathrm{pN}$ & $\mathrm{z}: 87.14 \mathrm{pN}$ & $\mathrm{z}:-196.50 \mathrm{pN}$ & $\mathrm{z}:-17.91 \mathrm{pN}$ \\
\hline \multirow{2}{*}{$\begin{array}{c}V=0.3 \mathrm{~V}, \rho_{N}=-1 \mathrm{mC} / \mathrm{m}^{2}, \\
\rho_{p}=-1 \mathrm{mC} / \mathrm{m}^{2}, r=500 \mathrm{~nm} \\
\text { (Figure 3c) }\end{array}$} & $\mathrm{x}: 8.50 \mathrm{pN}$ & $\mathrm{x}: 20.28 \mathrm{pN}$ & $\mathrm{x}:-16.76 \mathrm{pN}$ & $\mathrm{x}: 12.01 \mathrm{pN}$ \\
\hline & $\mathrm{z:} 77.97 \mathrm{pN}$ & $\mathrm{z}: 54.38 \mathrm{pN}$ & $\mathrm{z}:-174.59 \mathrm{pN}$ & $\mathrm{z}:-42.25 \mathrm{pN}$ \\
\hline \multirow{2}{*}{$\begin{array}{c}V=0.3 \mathrm{~V}, \rho_{N}=-1 \mathrm{mC} / \mathrm{m}^{2}, \\
\rho_{p}=-1 \mathrm{mC} / \mathrm{m}^{2}, r=2.25 \mu \mathrm{m} \\
\text { (Figure } 4 \mathrm{~d} \text { ) }\end{array}$} & $\mathrm{x}:-0.43 \mathrm{nN}$ & $\mathrm{x}: 0.07 \mathrm{nN}$ & $\mathrm{x}: 1.94 \mathrm{nN}$ & $\mathrm{x}: 1.58 \mathrm{nN}$ \\
\hline & $\mathrm{z}: 1.93 \mathrm{nN}$ & $\mathrm{z}: 0.27 \mathrm{nN}$ & $\mathrm{z:}-4.81 \mathrm{nN}$ & $\mathrm{z:}-2.61 \mathrm{nN}$ \\
\hline \multirow{2}{*}{$\begin{array}{c}V=0.5 \mathrm{~V}, \rho_{N}=-1 \mathrm{mC} / \mathrm{m}^{2}, \\
\rho_{p}=-1 \mathrm{mC} / \mathrm{m}^{2}, r=2.25 \mu \mathrm{m} \\
\text { (Figure 4e) }\end{array}$} & $\mathrm{x}:-0.38 \mathrm{nN}$ & $\mathrm{x}: 0.08 \mathrm{nN}$ & $\mathrm{x}: 0.28 \mathrm{nN}$ & $\mathrm{x}:-0.02 \mathrm{nN}$ \\
\hline & $\mathrm{z}: 2.16 \mathrm{nN}$ & $\mathrm{z}: 0.52 \mathrm{nN}$ & $\mathrm{z:}-3.04 \mathrm{nN}$ & $\mathrm{z}:-0.37 \mathrm{nN}$ \\
\hline \multirow{2}{*}{$\begin{array}{c}V=0.5 \mathrm{~V}, \rho_{N}=-1 \mathrm{mC} / \mathrm{m}^{2}, \\
\rho_{p}=-1 \mathrm{mC} / \mathrm{m}^{2}, r=375 \mathrm{~nm} \\
\text { (Figure 5d) }\end{array}$} & $\mathrm{x}: 10.14 \mathrm{pN}$ & $\mathrm{x}: 13.89 \mathrm{pN}$ & $\mathrm{x}:-24.78 \mathrm{pN}$ & $\mathrm{x}:-0.76 \mathrm{pN}$ \\
\hline & $\mathrm{z}: 74.01 \mathrm{pN}$ & $\mathrm{z}: 74.55 \mathrm{pN}$ & z: $-193.36 \mathrm{pN}$ & $\mathrm{z}:-44.80 \mathrm{pN}$ \\
\hline \multirow{2}{*}{$\begin{array}{c}V=0.5 \mathrm{~V}, \rho_{N}=-1 \mathrm{mC} / \mathrm{m}^{2}, \\
\rho_{p}=-10 \mathrm{mC} / \mathrm{m}^{2}, r=375 \mathrm{~nm} \\
\text { (Figure 5e) }\end{array}$} & $\mathrm{x}: 10.94 \mathrm{pN}$ & $\mathrm{x}: 16.08 \mathrm{pN}$ & $\mathrm{x}:-24.51 \mathrm{pN}$ & $\mathrm{x}: 2.50 \mathrm{pN}$ \\
\hline & $\mathrm{z}: 75.64 \mathrm{pN}$ & $\mathrm{z}: 80.76 \mathrm{pN}$ & $\mathrm{z}:-194.80 \mathrm{pN}$ & $\mathrm{z}:-38.41 \mathrm{pN}$ \\
\hline \multirow{2}{*}{$\begin{array}{c}V=0.3 \mathrm{~V}, \rho_{N}=-1 \mathrm{mC} / \mathrm{m}^{2}, \\
\rho_{p}=10 \mathrm{mC} / \mathrm{m}^{2}, r=2.25 \mu \mathrm{m} \\
\text { (Figure 6d) }\end{array}$} & $\mathrm{x}:-0.41 \mathrm{nN}$ & $\mathrm{x}: 0.06 \mathrm{nN}$ & $\mathrm{x}:-0.12 \mathrm{nN}$ & $\mathrm{x}:-0.47 \mathrm{nN}$ \\
\hline & $\mathrm{z}: 1.94 \mathrm{nN}$ & $\mathrm{z}: 0.29 \mathrm{nN}$ & $\mathrm{z}:-2.27 \mathrm{nN}$ & $\mathrm{z}:-0.04 \mathrm{nN}$ \\
\hline \multirow{2}{*}{$\begin{array}{c}V=0.3 \mathrm{~V}, \rho_{N}=-1 \mathrm{mC} / \mathrm{m}^{2}, \\
\rho_{p}=10 \mathrm{mC} / \mathrm{m}^{2}, r=10.0 \mu \mathrm{m} \\
\text { (Figure 6e) }\end{array}$} & $\mathrm{x}:-0.33 \mathrm{nN}$ & $\mathrm{x}: 0.17 \mathrm{nN}$ & $\mathrm{x}: 0.37 \mathrm{nN}$ & $\mathrm{x}: 0.21 \mathrm{nN}$ \\
\hline & $\mathrm{z}: 4.65 \mathrm{nN}$ & $\mathrm{z}: 1.90 \mathrm{nN}$ & $\mathrm{z}:-9.04 \mathrm{nN}$ & $\mathrm{z}:-2.49 \mathrm{nN}$ \\
\hline
\end{tabular}

